\title{
¿Para qué tantas sinapsis?
}

\section{A. Ferrús}

\author{
WHY SO MANY SYNAPSES?
}

Summary. Introduction and development. Synapses are the most abundant structures in the body of all animals. This number appears to be exceedingly large considering their apparent function: excite or inhibit the postsynaptic cell. In the few cases for which data are available, the number of synapses that two identified cells establish is reasonably constant between individuals although variable during development. Observations in a variety of sensory systems and animal species indicate that synapse number is important for normal physiology. Recent data from the olfactory system in Drosophila show that, if this number increases threefold, the sensitivity of perception increases up to three orders of magnitude. Similarly, the loss of perception sensitivity to a given odorant correlates with a loss of sensory synapses in selected neurons. These changes require proper regulation of the cAMP pathway. Conclusions. It seems reasonable to assume that the postsynaptic effects in the case of $N$ versus $N$ ' synapses should be different. Since the action potential parameters in the postsynaptic cell are the same in both cases, we can propose, as a working hypothesis, that the functional differences rely in the differential calcium dynamics throughout the postsynaptic dendritic branches. [REV NEUROL 2002; 35: 661-7]

Key words. Adaptation. Camp metabolism. Drosophila. Sensory perception. Synapse.

\section{INTRODUCCIÓN}

El número de células de un sistema nervioso se ha determinado con precisión sólo en el caso del gusano nematodo, Caenorhabdites elegans, y resultaron 302 (Tabla). Ese dato es constante entre individuos debido, entre otras razones, al desarrollo tan determinista de este animal. Otras especies en las que el desarrollo incluye procesos más regulativos, ofrecen variaciones más o menos apreciables en el número de células de núcleos determinados. Así, un cerebro humano adulto pesa, por término medio, $1,5 \mathrm{~kg}$, si bien la variabilidad es del $50 \%$. Puesto que el repertorio de comportamientos es aceptablemente homogéneo y constante entre humanos, este dato ya nos pone en guardia sobre la naturaleza de la que, a juicio de muchos, es la pregunta por excelencia en Neurobiología: ¿Cuáles son las diferencias estructurales entre cerebros que se comportan de forma diferente?

El peso del cerebro, como indicador del número de células, parece correlacionar con el tamaño del cuerpo más que con el repertorio de comportamientos [1]. En todo caso, parece evidente que la línea evolutiva de los homínidos se diferencia de la de los primates precisamente en la pendiente de esa correlación (Fig. 1). Si las diferencias no parecen radicar en el número de células, quizá lo sean en el número de contactos que establecen entre sí: las sinapsis. El número de estas estructuras suele utilizarse como símbolo de la inmensa complejidad estructural del cerebro. Así, en la región evolutivamente más reciente y que, por tanto, suele presentarse como sustrato de la condición humana de nuestra especie, la corteza cerebral, se estima que hay $10^{15}$ sinapsis. De forma todavía más espectacular: 'si se contasen a un ritmo de una por segundo, se tardarían 32 millones de años en completar la tarea'. Esas cifras cumplen el propósito de ilustrar la enormidad de la pregunta formulada anteriormente, pero se necesita afirmar también que el número de sinapsis no se ha contado nunca en ningún cerebro o núcleo

Recibido:03.09.02. Aceptadotras revisión externa sin modificaciones: 05.09.02. Instituto Cajal. CSIC. Madrid, España.

Correspondencia: Dr. A. Ferrús. Instituto Cajal. CSIC. Avda. Dr. Arce, 37. E-28002 Madrid. Fax: +34915854 754.E-mail: aferrus@cajal.csic.es C 2002, REVISTA DE NEUROLOGÍA cerebral de ninguna especie, entre otras razones porque existe el convencimiento de que ese número varía a lo largo del tiempo y, quizás, de forma rápida y drástica. No parece haber dudas de que la profusión de arborizaciones neurales y, por inferencia, de sinapsis, se relaciona íntimamente con la actividad. Así, la maduración de la percepción visual correlaciona con la retracción de ramas colaterales en neuronas de la corteza visual [2,3], y la adquisición de mapas espaciales complejos correlaciona con una notable exuberancia de ramificaciones en neuronas del hipocampo en humanos [4]. Tal como esos dos ejemplos ilustran, sin embargo, la correlación entre el refinamiento de la percepción y el número de sinapsis puede ser positiva o negativa.

Desde el postulado original de Donald Hebb [5] sobre la formación de la memoria como resultado en el cambio de sinapsis efectivas, los datos obtenido son bastante controvertidos en el terreno morfológico, mientras que son mucho más claros en el terreno funcional [6]. Así, fenómenos como la potenciación de larga duración (LTP) [7] o su contrapartida, la depresión de larga duración (LTD) [8], ofrecen propiedades celulares idóneas para explicar muchos aspectos macroscópicos del aprendizaje y la memoria [9], a pesar todavía de que estas formas de modulación de la fisiología sináptica no deben ser los únicos mecanismos que se pongan en juego [10]. Con todo, se admite tácitamente que la capacidad de los sistemas nerviosos para procesar aspectos de la realidad ambiental y generar y almacenar información compleja con gran precisión, es una consecuencia de la regulación del número de células y sinapsis durante el desarrollo y durante procesos dependientes de actividad $[11,12]$. Puesto que las ramificaciones neurales y la sinaptogénesis se relacionan claramente con el uso en múltiples especies [13-15], es razonable suponer que el amplio repertorio de comportamientos que ofrecen animales con grandes cerebros resulta de un número de sinapsis correspondientemente alto. Las demostraciones experimentales, sin embargo, no han sido fáciles de obtener y, cuando existen, suelen provenir de experimentos en los que se reduce el número efectivo de sinapsis, $\mathrm{N}$, normalmente tras intervención quirúrgica o farmacológica. Aquí, revisaremos casos en los que se modifica $\mathrm{N}$ mediante procedimientos genéticos en sistemas sensoriales de Drosophila. 


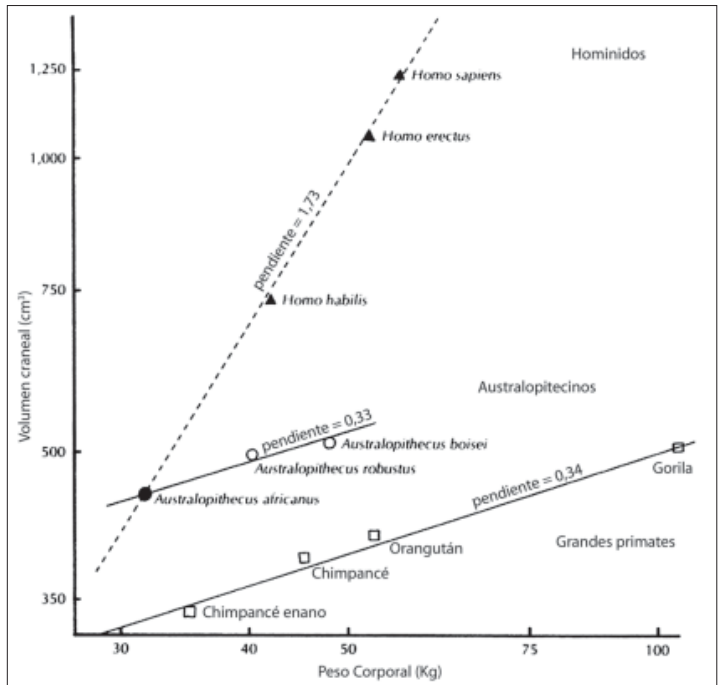

Figura 1. Relación entre el peso corporal y el volumen craneal de primates y homínidos. Representación logarítmica. Nótese la pendiente diferente para primates y australopitecinos de un lado $(0,3)$ y para los homínidos de otro $(1,7)$. Modificado de Pilbeam y Gould, 1976.

Tabla. Número aproximado de genes y neuronas en organismos seleccionados.

\begin{tabular}{lcl}
\hline Organismo & Genes & Neuronas \\
\hline Gusano C. elegans & 16.000 & 302 \\
\hline Mosca D. melanogaster & 12.000 & 250.000 \\
\hline Avispa enana & - & 5.000 \\
\hline Caracol marino Aplysia californicus & - & 20.000 \\
\hline Pulpo Octopus & - & 520 millones \\
\hline Ratón Mus musculus & 70.000 & 40 millones \\
\hline Humano Homo sap. sap. & 70.000 & 85.000 millones \\
\hline Elefante Elephas & 70.000 & 200.000 millones \\
\hline
\end{tabular}

Nota: estos números pueden considerarse exactos sólo para el caso de las neuronas de $C$. elegans. El resto son estimaciones sujetas a la definición (genes) 0 al método utilizado (neuronas). En todo caso, las diferencias proporcionales entre especies sí pueden considerarse próximas a la realidad.

\section{DEFINICIÓN Y COMPARACIÓN DE TÉRMINOS}

A lo largo de esta revisión, mantendremos la referencia a las ramificaciones, dendríticas o axonales, separadamente del término sinapsis. Por tanto, se entiende únicamente la estructura electrodensa rodeada de vesículas claras en el componente presináptico. Esta estructura suele admitirse como lugar preferente de fusión de vesículas con la membrana plasmática celular y, por tanto, lugar de liberación de neurotransmisor. Tal como se ha demostrado en las motoneuronas de insectos, las varicosidades que frecuentemente se observan en una ramificación axónica, no son el lugar exclusivo, aunque sí preferente, de localización de sinapsis, ni su número es coincidente con el de éstas [16]. Al tratarse de una estructura dinámica, la sinapsis puede presentarse bajo diversas formas de maduración. Los datos cuantitativos

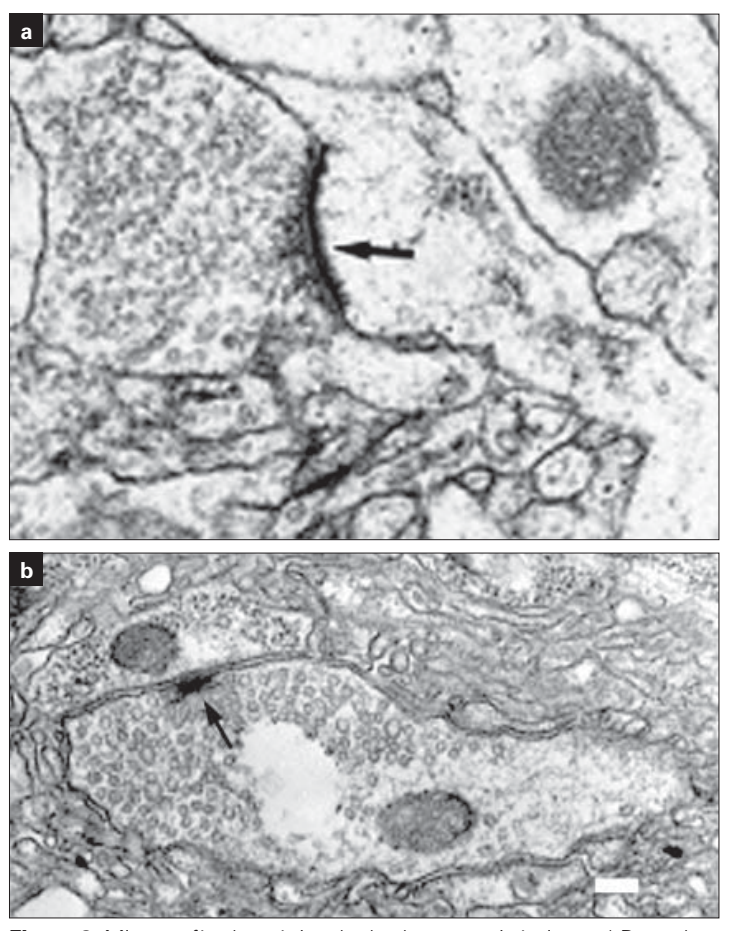

Figura 2. Micrografía electrónica de dos botones sinápticos. a) Procedente de la corteza somatosensorial humana. La flecha muestra la especialización electrodensa a cuyo lado presináptico se acumulan vesículas claras que contienen neurotransmisor; b) Procedente de la placa neuromuscular de una larva de Drosophila. Nótese la especialización electrodensa en forma de T (flecha) y el mismo tipo de vesículas que en A. Barra $=100 \mathrm{~nm}$. Imagen en (a) es una donación del Dr. De Felipe (I. Cajal, CSIC).

descritos en esta revisión consideran a una sinapsis como tal en cuanto puede distinguirse la especialización electrodensa, cualquiera que sea su tamaño o forma. La especialización sináptica madura en neuronas excitatorias de Drosophila adopta un perfil característico en T, por contraposición a la estructura correspondiente en humanos, que suele ser una barra simple a lo largo de la membrana plasmática (Fig. 2). Espinas dendríticas del tipo de las que se encuentran en neuronas piramidales de la corteza cerebral humana, se observan en Drosophila en neuronas postsinápticas del ganglio visual, pero no en los glomérulos olfativos, al igual como sucede en las estructuras humanas homólogas del lóbulo olfativo [17].

\section{EFECTOS FUNCIONALES DEL AUMENTO} DE N EN LA PERCEPCIÓN SENSORIAL

$\mathrm{El}$ aumento de $\mathrm{N}$ es una de las características de las neuronas mutantes para el gen gigas (gig) de Drosophila. Células homocigóticas para esta mutación aumentan sustancialmente su tamaño como consecuencia de las rondas adicionales de replicación de su ADN, que tienen lugar tras completar su ciclo normal de divisiones [18]. El gen codifica un homólogo del TSC2 humano, una proteína causante de tumores benignos que incluyen células gigantes endopoliploides [19]. En combinación con TSC1, TSC2 participa en el control del tamaño celular vía el receptor de insulina [20,21]. Aunque la mutación es letal, es posible generar 


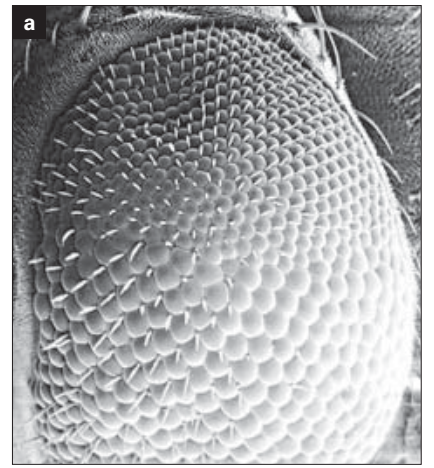

d
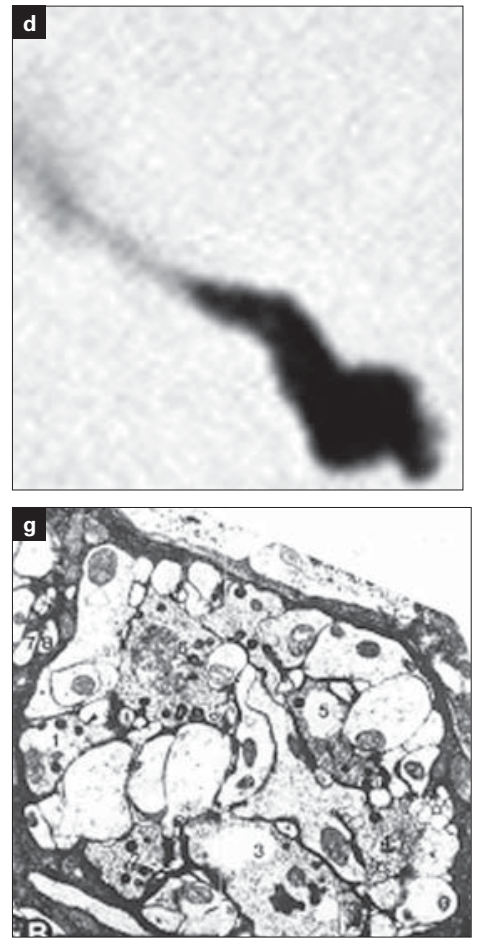
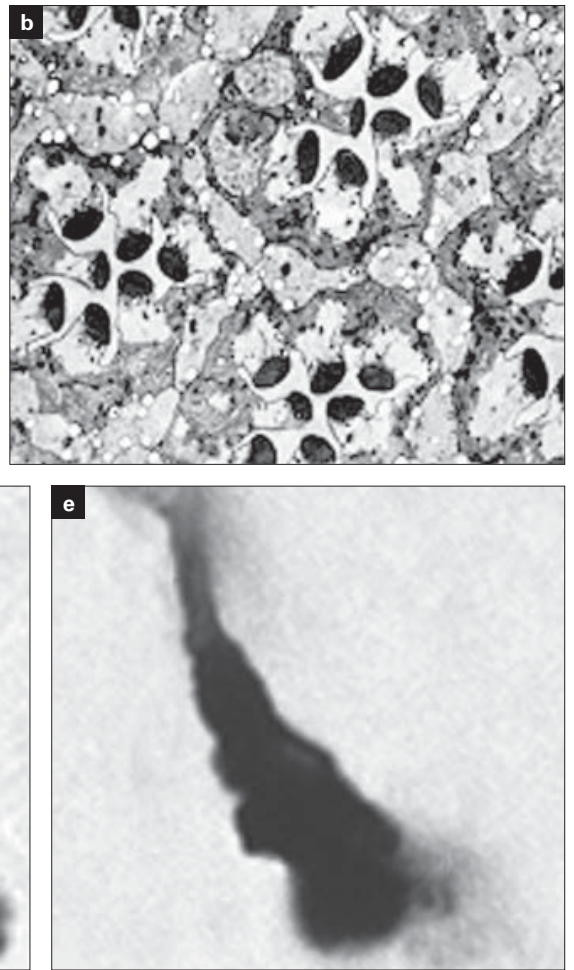

h

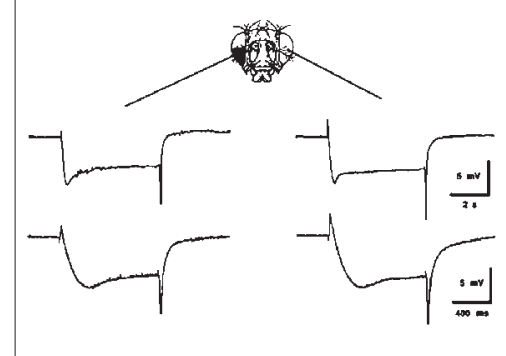

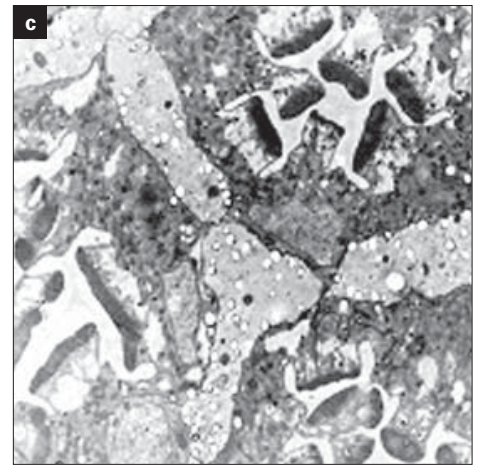

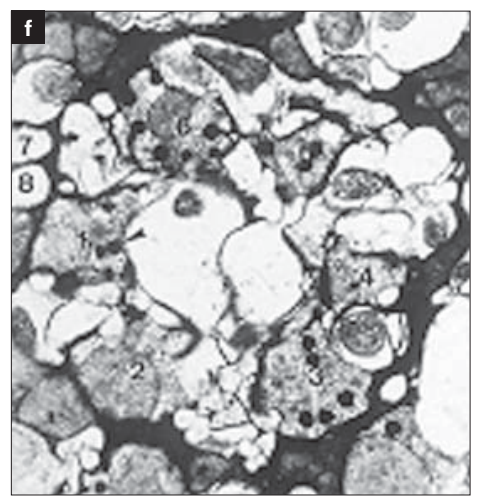

i

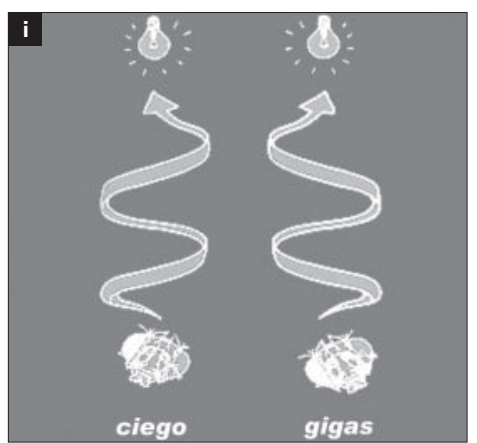

Figura 3. Efectos estructurales y funcionales de la mutación gigas en la percepción visual. a) Ojo mosaico mutante. El territorio dorsal es genéticamente normal y el ventral es mutante. Nótese el mayor tamaño de las ommatidias mutantes, pero que mantienen su ordenamiento normal; b) Sección a través de ommatidias de la región genéticamente normal. Nótese el apilamiento membranoso o rhabdomero de cada célula fotorreceptora; c) Idem del territorio mutante. Nótese el engrosamiento de cada célula incluidos los rabdómeros que, en algunos casos, aparecen múltiples; d) Impregnación de Golgi de un terminal axónico tipo R7 de genotipo normal; e) Ídem de un terminal mutante; f) Micrografía electrónica de un cartucho de la lámina en donde proyectan axones de fotorreceptores normales; g) Ídem de uno que recibe axones mutantes. Las neuronas intrínsecas de la lámina son genéticamente normales. Nótese el aumento de tamaño debido al engrosamiento de los axones mutantes; h) Electrorretinogramas obtenidos de un ojo mutante y su contralateral normal. Ambos son de aspecto y magnitud normales; i) Comportamiento fototáctico (ver texto). Nótese la trayectoria helicoidal hacia la fuente de luz que exhibe el ojo normal en los individuos mosaico gigas, mientras que, si éstos hubiesen sido mutantes ciego, el ojo exhibido sería el mutante. Las imágenes de estructuras normales y mutantes son de la misma magnificación.

mosaicos en los que, por ejemplo, sólo una fracción de la retina de un ojo se constituya de células homocigóticas para la mutación, mientras que en el resto del cuerpo las células permanecen heterocigóticas, $\mathrm{y}$, por tanto, de aspecto normal.

Individuos mosaicos de este tipo, mosaicos de ojo, se pueden someter a pruebas de fototaxia y estudiar diversos parámetros de su respuesta (Fig. 3). En individuos control, la respuesta a una fuente de luz suele ser atractiva y se manifiesta mediante una trayectoria recta hacia la fuente. Los mosaicos, por el contrario, acuden también a la fuente de luz, pero describen una trayectoria helicoidal en la que el ojo mutante permanece alejado de la fuente, y expone el ojo normal [18]. La probabilidad de esta respuesta es función de la extensión del territorio mutante en la retina mosaico. Este comportamiento anormal se acompaña de una alteración estructural documentada en secciones seriadas y observadas en el microscopio electrónico. El análisis cuantitativo de los cartuchos 

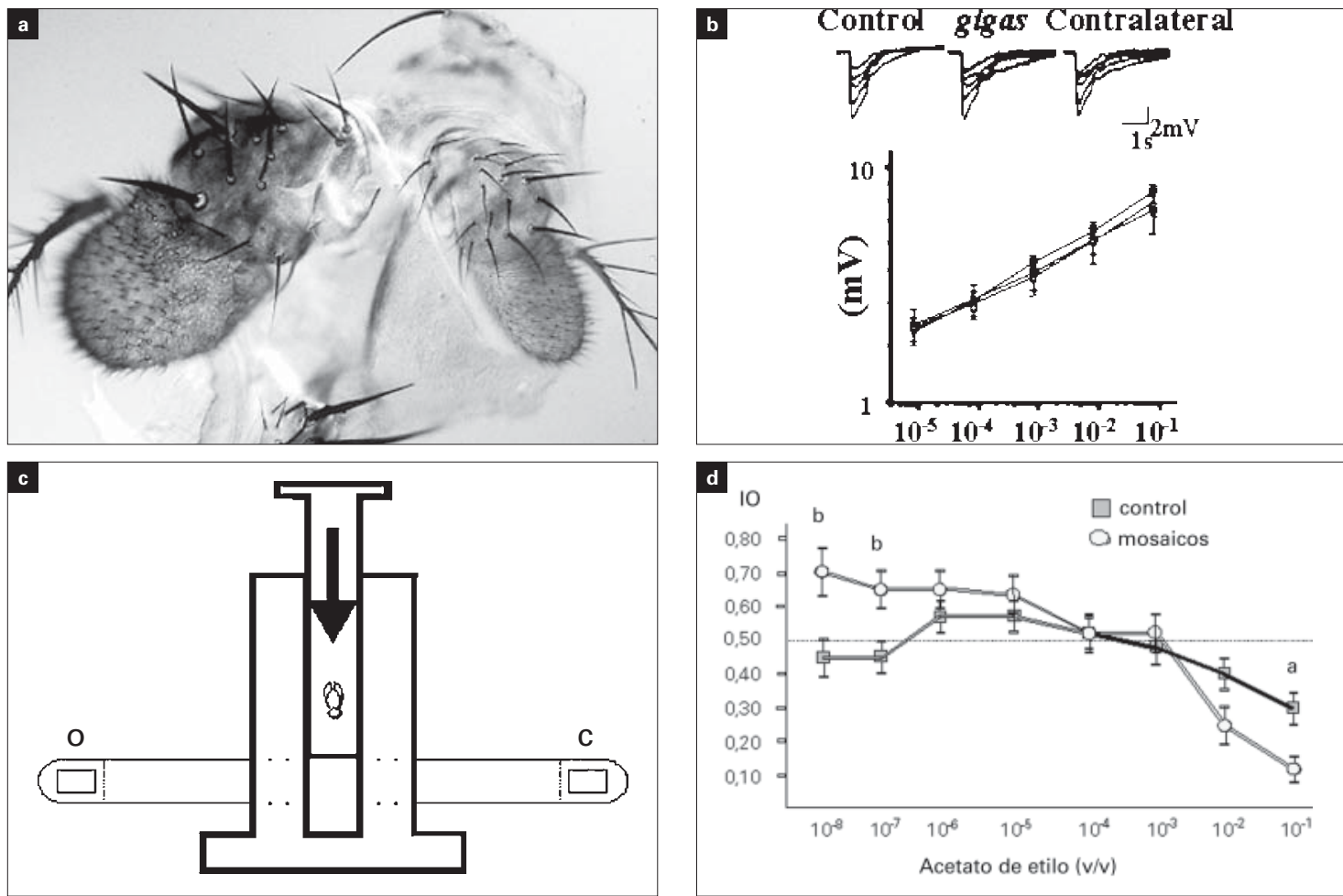

Figura 4. Efectos estructurales y funcionales de la mutación gigas en la percepción olfativa. a) Antena mutante (izquierda) y normal en el mismo individuo mosaico; b) Electrolfactogramas de antenas normales y mutantes estimuladas con concentraciones crecientes de acetato de etilo. Nótese, como en
los retinogramas de la figura 3, que la transducción sensorial es normal en el mutante; c) Laberinto enT para medir el índice olfativo de moscas individuales o en grupo (ver texto). En O se aloja un papel impregnado con acetato de etilo a concentración conocida. En C se aloja un papel identico impregnado hacia concentraciones bajas de la respuesta atrayente en los mosaicos, así como la mayor magnitud de las respuestas, atrayentes o repelentes, de los mosaicos. ${ }^{a} p<0,05 ;{ }^{b} p<0,005$.

ópticos, el lugar en donde los fotorreceptores de la retina forman un estereotipado patrón de contactos con las neuronas intrínsecas de la lámina, demuestra que, en el caso de fotorreceptores gigas, el número de sinapsis establecidas con las neuronas de la lámina -genéticamente normales- es de tres veces superior al normal. Conviene resaltar que el patrón de conectividad y el número de sinapsis que otros fotorreceptores adyacentes, genéticamente normales, establecen con las neuronas de la lámina, permanecen sin cambios. Es decir, el fenotipo gigas es autónomo celular. Estos hechos morfológicos sirven para demostrar que, al menos para el caso de las conexiones retina-lámina, es la neurona sensorial la que impone el número de sinapsis que se han de establecer. La neurona postsináptica de la lámina se limita a servir cuantas sinapsis se demandan por cada fotorreceptor, incluso cuando en una misma neurona de la lámina convergen fotorreceptores mutantes y normales [18]. El comportamiento fototáctico de los mosaicos gigas sugiere que la retina mutante transmite un 'exceso' de estimulación que, en todo caso, se interpreta adecuadamente por el cerebro y resulta en un comportamiento coherente. No obstante, la mutación también altera el tamaño de la córnea, una estructura secretada por células especializadas y que actúa como lente en cada ommatidia. Con ello, es evidente que el ángulo de entrada de cada haz luminoso se modificará, lo que, probablemente, distorsione la imagen en aspectos que no se pueden estu- diar adecuadamente. Los electrorretinogramas, al menos, no muestran diferencias notables entre un ojo mutante y su contralateral normal. Sería deseable, pero técnicamente irrealizable por ahora, poder obtener registros intracelulares en lugar de potenciales sensoriales de campo.

Una alternativa para analizar de forma cuantitativa la respuesta comportamental de estos mosaicos, sin problemas como los descritos, es utilizar otra modalidad sensorial, la olfacción. La organización estructural de este sistema es muy similar en insectos y humanos [22]. En Drosophila, cada antena contiene unas 1.500 neuronas sensoriales que expresan alguno de los 57 receptores olfativos conocidos hasta hoy, y proyectan a los 43 glomérulos que componen el lóbulo antenado [23,24]. Con los datos actuales, tanto en Drosophila como en el ratón, parece que cada neurona olfativa expresa un sólo tipo de receptor y las neuronas que expresan un mismo receptor convergen en el mismo glomérulo, de tal forma que puede hablarse de un mapa odotópico [25]. El procesamiento de los estímulos olfativos origina representaciones combinatorias de actividad glomerular, tanto en insectos [26] como en mamíferos [27]. Finalmente, estos mapas glomerulares se transforman en patrones de actividad sináptica [28] en sus proyecciones a otros centros de integración, tales como el cuerpo pedunculado en insectos o la corteza piriforme en mamíferos. 

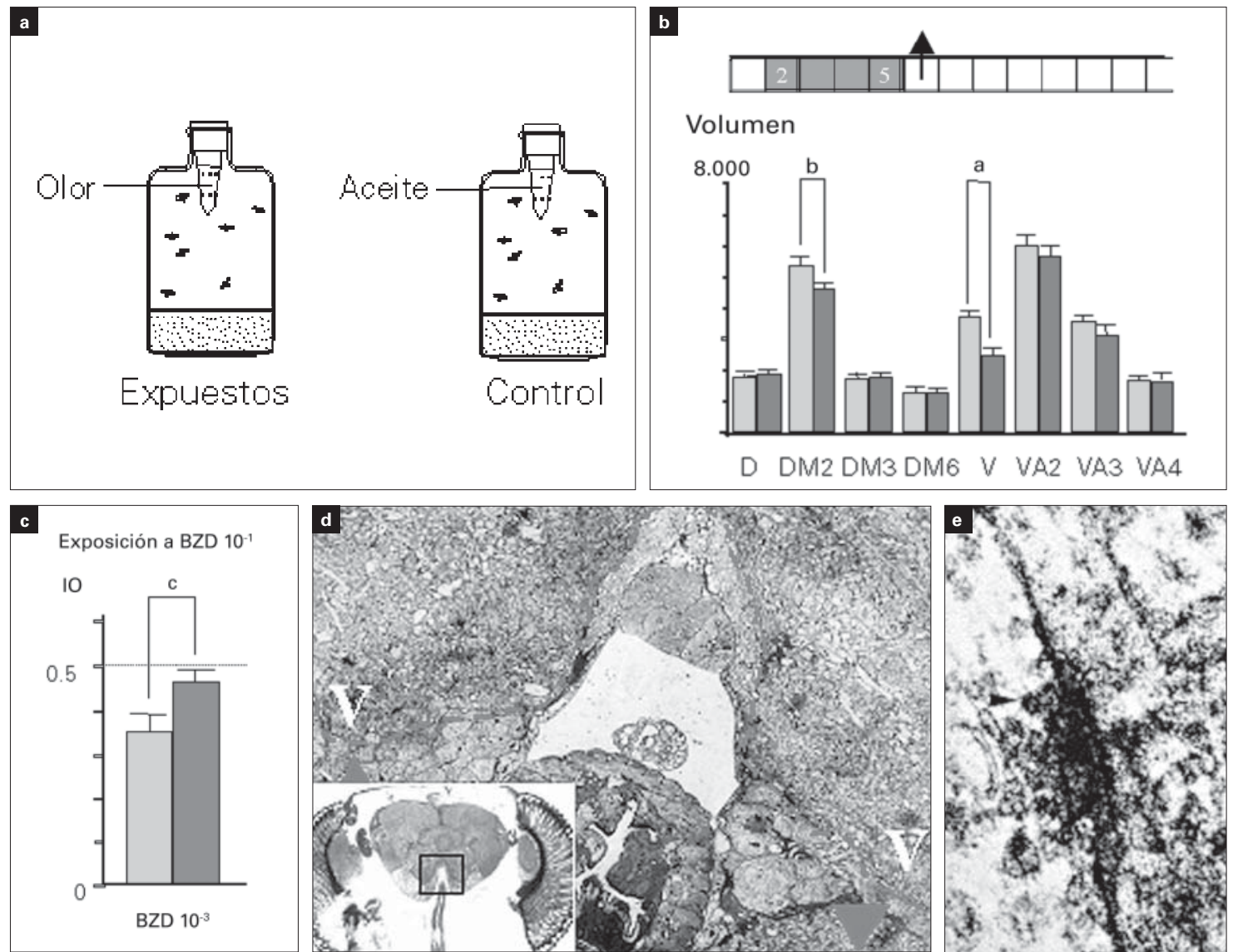

Figura 5. Adaptación olfativa. a) Método de exposición de adultos al benzaldehído concentrado. b) Las moscas expuestas durante los días 2 al 5 de vida se analizan el día 6 en el microscopio con focal, para medir el volumen de glomérulos olfativos identificados. Nótese la reducción significativa y específica de los glomérulos DM2 y V en los individuos expuestos a benzaldehído (BZD). c) Adaptación de la respuesta comportamental a BZD (10-3 v/v) en los individuos expuestos $\left(10^{-1} \mathrm{v} / \mathrm{v}\right) ; \delta$ (densidad) $=1,54 \pm 0,40$ (controles), 1,23 $\pm 0,21$ (expuestos), $-20 \% ; v$ (volumen) $=3.695 \pm 273$ (controles), $2.490 \pm 262$ (expuestos), $-33 \%$, el numero de sinapsis aparece reducido aproximadamente un $30 \%$ respecto a los controles. d) Estimación del cambio en el número de sinapsis en el glomérulo $V$ tras la exposición a BZD. Se muestra una sección frontal de $3 \mu \mathrm{m}$ con indicación del glomérulo $\mathrm{V}$. e) Se muestra una micrografía electrónica de una zona electrodensa.

Individuos mosaicos para la mutación gigas en los que una antena expresa la condición gig, mientras que el resto del cuerpo, incluidas las neuronas de segundo orden de los glomérulos olfativos, expresa el fenotipo normal, pueden someterse a pruebas funcionales, así como a estudios morfológicos detallados. Efectuados los correspondientes estudios morfológicos, el incremento de $\mathrm{N}$ en esta vía sensorial resulta ser del mismo orden que en la vía visual, un $300 \%$. Asimismo, y al igual que en la retina, las neuronas sensoriales gig mantienen el mapa de proyecciones inalterado [29]. Al igual que los electrorretinogramas, también los electroantenogramas de una antena mutante, comparados con los de su homóloga contralateral normal, muestran la misma sensibilidad y amplitud de respuesta a estimulación olfativa con un amplio intervalo de concentraciones (Fig. 4).

El comportamiento olfativo, por el contrario, se diferencia apreciablemente en los mosaicos con respecto a sus controles -individuos hermanos sometidos al mismo tratamiento, pero sin territorio mutante-(Fig. 4). Si utilizamos un sencillo laberinto en $\mathrm{T}$, las moscas pueden someterse a un ensayo de elección entre dos compartimentos impregnados con un olor diferente cada uno. La versión más sencilla de este ensayo consiste en ofrecer la elección entre un olor a una concentración determinada frente al disolvente (normalmente, aceite de parafina). La respuesta de individuos normales a un intervalo de concentraciones es muy estereotipada: indiferencia a concentraciones muy bajas, atracción a concentraciones moderadas y repulsión a concentraciones muy elevadas [30]. Ese patrón se reproduce para cualquier olor, y solo varían las concentraciones a las que se produce cada tipo de respuesta y la amplitud de la misma según el olor ensayado. En los mosaicos, el patrón general de respuesta es normal, pero, a diferencia de los controles, las respuestas atrayentes se observan a concentraciones tan bajas $\left(10^{-8}-10^{-5}\right.$ de acetato de etilo), que resultan indiferentes para los controles. El comportamiento de repulsión se mantiene a concentraciones altas, tal como los controles, pero, tanto en la repulsión como en la atracción se detecta una segunda diferencia en los mosaicos, la magnitud de la respuesta. En ambos casos, el índice de respuesta es el doble en los mosaicos (Fig. 4). Tomados en conjunto, estos resultados permiten concluir que: 
a) El aumento de $\mathrm{N}$ dota al animal de un aumento de sensibilidad de la percepción, entendida ésta como fenómeno central y distinto de la sensibilidad de los receptores sensoriales que permanece inalterada en gigas, ya que los electroantenogramas no cambian.

b) El presunto aumento de entrada sensorial no lo filtra el sistema y se interpreta coherentemente.

c) El aumento de $\mathrm{N}$ afecta de forma independiente al procesamiento de las respuestas atrayentes -desplazamiento de la respuesta hacia concentraciones más bajas-con respecto a las repelentes -no hay desplazamiento-, y quizá refleja que éste tiene lugar en núcleos cerebrales diferentes.

d) El aumento de $\mathrm{N}$ repercute, además, en la magnitud de la respuesta comportamental y la aumenta, tanto si es atractiva como repelente.

Hasta aquí parece evidente que $\mathrm{N}$ es un parámetro importante, cuyo control determina varios aspectos del comportamiento. Tras estos resultados debidos a un aumento de $\mathrm{N}$, cabría esperar una serie opuesta de cambios si $\mathrm{N}$ disminuye.

\section{EFECTOS ESTRUCTURALES}

\section{EN LA ADAPTACIÓN A UN ESTÍMULO SENSORIAL}

Con el mismo sistema sensorial que con los mosaicos gigas, examinamos los efectos estructurales y funcionales de la exposición de adultos jóvenes a un olor, y el propósito de este tipo de experimentos es intentar correlacionar cambios de comportamiento con cambios neuronales (Fig. 5). Los animales se expusieron durante cuatro días a una alta concentración, $10^{-1} \mathrm{v} / \mathrm{v}$, del olor seleccionado y posteriormente sometidos a una prueba comportamental o a un análisis morfológico cuantitativo de los glomérulos olfativos. En el ensayo de elección en el laberinto en T se observa una adaptación de la respuesta en los animales expuestos al olor con respecto a los controles expuestos al disolvente (Fig. 5). Se trata, pues, de un cambio de comportamiento. Dicha adaptación resultó específica de olor y achacable a cambios centrales en lugar de periféricos, ya que los electroantenogramas no muestran cambio alguno. Por el contrario, en los glomérulos, medidos en secciones confocales, se observa una reducción de volumen que, al igual que la respuesta comportamental, resulta específica del olor utilizado. Todavía más, en el caso del glomérulo V, reducido su volumen como consecuencia de la exposición a benzaldehído, se observa además una reducción del número de sinapsis $\mathrm{N}$, que alcanza a ser del $30 \%$; un valor que, probablemente, esté en consonancia con el de gigas y los respectivos efectos en la percepción. Por último, tanto la adaptación como los cambios volumétricos en glomérulos específicos no tienen lugar si el animal es mutante para el gen dunce o rutabaga. Estos dos genes codifican enzimas -fosfodiesterasa II y la subunidad catalítica de la adenilato ciclasa- que regulan los niveles de AMPc citoplásmico. En el primer caso, los niveles de este nucleótido cíclico se elevan crónicamente, y en el segundo, se reducen. Es probable, por consiguiente, que tanto la adaptación como la reducción de $\mathrm{N}$ sean fenómenos celulares basados en ese mecanismo molecular; un mecanismo, por cierto, también necesario en procesos de aprendizaje asociativo, tanto en Drosophila como en el ratón [31].

Tomados en su conjunto, los datos obtenidos de los experimentos de adaptación demuestran que existe un cambio de $\mathrm{N}$ y que éste consiste en una reducción específica de glomérulo y de olor. A su vez, al considerar los datos con el mutante gigas, en donde $\mathrm{N}$ aumenta y también lo hace la sensibilidad de la percepción, resulta evidente que $\mathrm{N}$ tiene un significado biológico importante que debe ir mas allá de representar un 'factor de seguridad' en la transmisión de una señal, excitatoria o inhibitoria, a la célula postsináptica.

\section{UNA HIPÓTESIS DE TRABAJO}

No existen todavía datos electrofisiológicos sobre las consecuencias postsinápticas de un aumento (o reducción) de N. En todo caso, es lógico predecir que la presencia de nuevas sinapsis debe ocasionar una aglomeración de receptores del neurotransmisor correspondiente en nuevos lugares del árbol dendrítico. Directa o indirectamente, la activación de receptores postsinápticos suele ocasionar un aumento transitorio en la concentración de $\mathrm{Ca}^{2+}$, que se neutraliza rápidamente por los eficaces sistemas de taponamiento. De hecho, se conocen muchas proteínas con capacidad para unir $\mathrm{Ca}^{2+}(>100)$, la mayoría con abundante presencia en las espinas dendríticas. El fenómeno debe ser particularmente relevante en el restringido espacio de una espina y esto ha sido el fundamento de numerosas propuestas sobre la capacidad de las espinas para retraer su pedúnculo y, con ello, 'desconectar' transitoriamente esa sinapsis.

Independientemente de si ese fenómeno tiene lugar o no, pero en el contexto de la demostrada dinámica del $\mathrm{Ca}^{2+}$, se pueden proponer los siguientes sucesos para el caso de gigas:

1. Al aumentar los sitios postsinápticos de activación, la elevación de $\mathrm{Ca}^{2+}$ debe ser también mayor.

2. Si una de las nuevas sinapsis se localiza muy próxima a la nativa anterior, la concentración local puede alcanzar valores críticos que repercutan en la citoarquitectura local en forma sinérgica.

3. Si las nuevas sinapsis se alejan de las nativas, la extensión del árbol dendrítico que se activa ahora será mucho mayor lo que debe provocar; entre otros, un retraso en la eliminación del $\mathrm{Ca}^{2+}$ citoplásmico, es decir, una huella o memoria celular de más larga duración y extensión.

4. Esa huella debe afectar la probabilidad de disparo de un segundo potencial de acción en la célula postsináptica. Es decir, en gigas cabría esperar un cambio en la frecuencia de disparo de las neuronas, genéticamente normales, que reciben inervación mutante.

De esa forma, se puede concebir que el lenguaje neural se modifique sin alterar los parámetros básicos de la fisiología celular. Por extensión, la percepción puede resultar en un cambio en el número efectivo de sinapsis si el mantenimiento de éstas depende, en cierta medida, de su utilización [32]. Con ello, la respuesta a la pregunta formulada en el título parece ser: 'Para sobrevivir en un mundo competitivo'.

\section{BIBLIOGRAFÍA}

1. Holt AB, Cheek DB, Mellits ED, Hill DE. Brain size and the relation of the primate to the nonprimate. In Cheek DB, ed. Fetal and postnatal cellular growth: hormones and nutrition. New York: John Wiley; 1975. p. $23-44$.
2. Valverde F. Apical dendritic spines of the visual cortex and light deprivation in the mouse. Exp Brain Res 1967; 3: 337-52

3. Innocenti GM, Fiore L, Caminiti R. Exhuberant projection into the corpus callosum from the visual cortex of newborn cats. Neurosci Lett 1977; 4: 237-42. 
4. Maguire EA, Gadian DG, Johnsrude IS, Good CD, Ashburner J, Frackowiak RS, et al. Navigation-related structural change in the hippocampi of taxi drivers. Proc Natl Acad Sci U S A 2000; 97: 4398-403.

5. Hebb DO. The organization of behavior. New York: Wiley \& Sons; 1949.

6. Moser MB. Making more synapses: a way to store information? Cell Mol Life Sci 1999; 55 : 593-600.

7. Bliss TVP, Lomo T. Long lasting potentiation of synaptic transmission in the dentate gyrus of the anaesthetized rabbit following stimulation of the perforant path. J Physiol 1973; 232: 331-56.

8. Ito M. Long-term depression. Annu Rev Neurosci 1989; 12: 85-102.

9. Maren S, Baudry M. Properties and mechanisms of long-term synaptic plasticity in the mammalian brain: relationships to learning and memory. Neurobiol Learn Mem 1995; 63: 1-18.

10. Hölscher C. Long-term potentiation: a good model for learning and memory? Progr Neuropsychopharmacol Biol Psychiatry 1997; 121: 47-68.

11. Goodman CS, Shatz CJ. Developmental mechanisms that generate precise patterns of neuronal connectivity. Cell 1993; 72 (Suppl): 77-98.

2. Vaux DL, Korsmeyer SJ. Cell death in development. Cell 1999; 96: 245-54.

3. Bailey CH, Kandel ER. Structural changes accompanying memory storage. Annu Rev Neurosci 1993; 55: 397-426.

14. Heisenberg M, Heusipp M, Wanke C. Structural plasticity in the Drosophila brain. J Neurosci 1995; 15: 1951-60.

15. Rajan I, Cline HT. Glutamate receptor activity is required for normal development of tectal cell dendrites in vivo. J Neurosci 1998; 18 : develop

16. Atwood HL, Govind CK, Wu CF. Differential ultrastructure of synaptic terminals on ventral longitudinal abdominal muscles in Drosophila larvae. J Neurobiol 1993; 24: 1008-24.

17. Atwood HL, Karunanithi S. Diversification of synaptic strength: Presynaptic elements. Nat Rev Neurosci 2002; 3: 497-516.

18. Canal I, Fariñas I, Gho M, Ferrús A. The presynaptic cell determines the number of synapses in the Drosophila optic ganglia. Eur J Neurosci 1994; 6: 1423-31.

\section{¿PARA QUÉ TANTAS SINAPSIS?}

Resumen. Introducción y desarrollo. La sinapsis es la estructura más abundante en el cuerpo de cualquier animal. Este número parece excesivamente grande al considerar su finalidad aparente: excitar o inhibir la célula postsináptica. Por otro lado, en los pocos casos de los que se dispone de datos, el número de sinapsis que dos células identificadas establecen entre sí suele ser razonablemente constante entre individuos, aunque varía durante el desarrollo. Observaciones procedentes de varios sistemas sensoriales y especies animales indican que el número de sinapsis es importante. En el sistema olfativo de Drosophila, si ese número aumenta tres veces, la sensibilidad de la percepción aumenta hasta tres órdenes de magnitud. Del mismo modo, la pérdida de sensibilidad de percepción olfativa a un determinado olor correlaciona con la pérdida de sinapsis sensoriales en determinadas neuronas. Esos cambios tienen lugar mediante la participación del AMPc y sus reguladores. Conclusiones. Parece lógico suponer que los efectos postsinápticos en el caso de N sinapsis con respecto al caso N' deben ser diferentes. Puesto que los parámetros del potencial de acción postsináptico en ambos casos son los mismos, cabe proponer, como hipótesis de trabajo, que la diferencia de significado biológico radica en la diferente dinámica del calcio a lo largo de la geometría de la célula postsináptica. [REV NEUROL 2002; 35: 661-7]

Palabras clave. Adaptación. Drosophila. Metabolismo del AMPc. Percepción sensorial. Sinapsis.
19. Ito N, Rubin GM. Gigas, a Drosophila homolog of tuberous sclerosis gene product-2, regulates the cell cycle. Cell 1999; 96: 529-39.

20. Brogiolo W, Stocker H, Ikeya T, Rintelen F, Fernández R, Hafen E. An evolutionarily conserved function of the Drosophila insulin receptor and insulin-like peptides in growth control. Curr Biol 2001; 11:213-21.

21. Oldham S, Stocker H, Laffargue M, Wittwer F, Wymann M, Hafen E. The Drosophila insulin/IGF receptor controls growth and size by modulating PtdInsP(3) levels. Development 2002; 129: 4103-9.

22. Hildebrand JG, Shepherd GM. Mechanisms of olfactory discrimination: converging evidence for common principles across phyla. Annu Rev Neurosci 1997; 20: 595-631.

23. Vosshall LB, Wong AM, Axel R. An olfactory sensory map in the fly brain. Cell 2000; 102: 147-59.

24. Laissue PP, Reiter C, Hiesinger PR, Halter S, Fischbach KF, Stocker RF. Three-dimensional reconstruction of the antennal lobe in Drosophila melanogaster. J Comp Neurol 1999; 405: 543-52.

25. Gao Q, Yuan B, Chess A. Convergent projections of Drosophila olfactory neurons to specific glomeruli in the antennal lobe. Nat Neurosci 2000; 3: 780-5.

26. Galizia CG, McIlwrath SL, Menzel R. A digital three-dimensional atlas of the honeybee antennal lobe based on optical sections acquired by confocal microscopy. Cell Tissue Res 1999; 295: 383-94.

27. Rubin BD, Katz LC. Optical imaging of odorant representations in the mammalian olfactory bulb. Neuron 1999; 23: 499-511.

28. Laurent G. A systems perspective on early olfactory coding. Science 1999; 286: 723-8.

29. Acebes A, Ferrús A. Increasing the number of synapses modifies olfactory perception in Drosophila. J Neurosci 2001; 21: 6264-73.

30. Ayyub CH, Paranjape J, Rodrigues V, Siddiqi O. Genetics of olfactory behavior in Drosophila melanogaster. J Neurogenet 1990; 6: 243-62.

31. Dubnau J, Tully T. Gene discovery in Drosophila: new insights for learning and memory. Annu Rev Neurosci 1998; 21: 407-44.

32. González-Forero D, Álvarez FJ, de la Cruz R, Delgado-García JM, Pastor AM. Influence of afferent synaptic innervations on the discharge variability of cat abducens motoneurons. J Physiol 2002; 541: 283-99.

\section{TANTAS SINAPSES PARA QUE?}

Resumo. Introdução e desenvolvimento. A sinapse é a estrutura mais abundante no corpo de qualquer animal. Este número parece excessivamente grande considerando a sua finalidade aparente: excitar ou inibir a célula pós-sináptica. Por outro lado, nos poucos casos em existem dados disponíveis, o número de sinapses que duas células identificadas estabelecem entre si, é habitualmente razoavelmente constante entre indivíduos embora varie durante o desenvolvimento. Observações procedentes de vários sistemas sensoriais e espécies animais indicam que o número de sinapses é importante. No sistema olfactivo de Drosophila, se esse número aumenta três vezes, a sensibilidade da percepção aumenta até três ordens de grandeza. Da mesma forma, a perda de sensibilidade de percepção olfactiva a um determinado cheiro correlaciona com a perda de sinapses sensoriais em determinados neurónios. Essas alterações têm lugar durante a participação do AMPce seus reguladores. Conclusões. Parece lógico supor que os efeitos pós-sinápticos no caso de $N$ sinapses em relação ao caso $N$ ' devem ser diferentes. Posto que os parâmetros de potencial de acção são os mesmos em ambos os casos, cabe propor, como hipótese de trabalho, que a diferença de significado biológico baseia-se na diferente dinâmica do cálcio e ao longo a geometria da célula pós-sináptica. [REV NEUROL 2002; 35: 661-7]

Palavras chave. Adaptação. Drosophila. Metabolismo do AMPc. Percepção sensorial. Sinapse. 